\title{
Model Organisms in the Fight against Muscular Dystrophy: Lessons from Drosophila and Zebrafish
}

\author{
Emilie Plantié ${ }^{1, \dagger}$, Marta Migocka-Patrzałek ${ }^{2, \dagger}$, Małgorzata Daczewska ${ }^{2}$ and Krzysztof Jagla ${ }^{1, *}$ \\ 1 GReD (Genetics, Reproduction and Development laboratory), INSERM U1103, CNRS UMR6293, \\ University of Clermont-Ferrand, 28 place Henri-Dunant, 63000 Clermont-Ferrand, France; \\ E-Mail: emilie.plantie@udamail.fr \\ 2 Department of Animal Developmental Biology, Institute of Experimental Biology, \\ University of Wroclaw, 21 Sienkiewicza Street, 50-335 Wroclaw, Poland; \\ E-Mails: marta.migocka-patrzalek@uni.wroc.pl (M.M.-P.); malgorzata.daczewska@uni.wroc.pl (M.D.) \\ $\uparrow$ These authors contributed equally to this work. \\ * Author to whom correspondence should be addressed; E-Mail: christophe.jagla@udamail.fr; \\ Tel.: +33-473178181; Fax: +33-473276132.
}

Academic Editor: Leonidas A. Phylactou

Received: 24 February 2015 / Accepted: 1 April 2015 / Published: 9 April 2015

\begin{abstract}
Muscular dystrophies (MD) are a heterogeneous group of genetic disorders that cause muscle weakness, abnormal contractions and muscle wasting, often leading to premature death. More than 30 types of MD have been described so far; those most thoroughly studied are Duchenne muscular dystrophy (DMD), myotonic dystrophy type 1 (DM1) and congenital MDs. Structurally, physiologically and biochemically, MDs affect different types of muscles and cause individual symptoms such that genetic and molecular pathways underlying their pathogenesis thus remain poorly understood. To improve our knowledge of how MD-caused muscle defects arise and to find efficacious therapeutic treatments, different animal models have been generated and applied. Among these, simple non-mammalian Drosophila and zebrafish models have proved most useful. This review discusses how zebrafish and Drosophila MD have helped to identify genetic determinants of MDs and design innovative therapeutic strategies with a special focus on DMD, DM1 and congenital MDs.
\end{abstract}


Keywords: muscular dystrophies; animal models; Drosophila; zebrafish; pathophysiology; therapeutic screens

\section{Introduction}

Muscular dystrophies (MDs) are a heterogeneous group of inherited rare disorders primarily affecting the muscle system, causing progressive skeletal muscle weakness, and often associated with cardiomyopathy and respiratory problems [1,2]. Duchenne MD (DMD), Becker MD (BMD), Limb-Girdle MD (LGMD), myotonic dystrophy type 1 (DM1), oculo-pharyngeal MD (OPMD), fascio-scapulo-humeral MD (FSHMD), Emery-Dreifuss MD (EDMD), distal muscular dystrophy (DD) and congenital MD (CMD) are the nine most common muscular dystrophies. Among them, DMD caused by the mutation in the Dystrophin gene identified more than twenty years ago [3-5] still has no effective therapy, illustrating a lasting need to find efficacious treatments for MDs.

Due to technical and ethical reasons, it is not always possible to investigate disease processes directly in humans. Model organisms, both mammalian and non-mammalian, are essential to understanding normal and pathological muscle development in humans. The major non-mammalian animal models, the fruitfly Drosophila melanogaster, the zebrafish Danio rerio and the nematode Caenorhabditis elegans, are considered useful alternatives for studying human diseases and particularly muscular dystrophies [3]. Among them, Drosophila melanogaster has been used as a model organism for over 100 years, particularly in genetics, where it was useful to better understand the concept of trait heritability [4,5]. The fruitfly genome was fully sequenced in 2000 [6], revealing that key physiological processes and disease-related genes are well-conserved between flies and humans [7,8], making it a model of choice for these studies. Finally, the availability of Drosophila transgenic and mutant line collections facilitates functional analyses of disease genes. Compared with the fruitfly, the worm, owing to a lack of muscle cell fusion, restricted gene conservation and a short lifespan, appears suitable for studying only some aspects of muscle defects observed in MDs.

By contrast, the vertebrate model zebrafish conserves the majority (84\%) of the genes known to be associated with human diseases, both rare and common [9], with significant degrees of synteny between the conserved genes [10]. The zebrafish offers many advantages: it can quickly produce a large number of externally developing, diploid embryos; the transparency of zebrafish embryos and larvae allows real-time imaging of all developmental stages; and the genome sequence, as for Drosophila, is available [9]. To generate disease models, three main methods are used in zebrafish: morpholino-mediated knockdown [11,12]; $N$-ethyl- $N$-nitrosourea (ENU) mutagenesis [13], which is widely used to identify new genes involved in muscles diseases [14-17]; and finally genome-editing technologies such as the clustered regularly interspaced short palindromic repeats technique (CRISPR), successfully used in both zebrafish [18-20] and Drosophila [21,22].

Importantly, besides gene conservation, Drosophila and zebrafish muscles share many structural, histological and functional similarities with human muscle [23-25]. These similarities further support the view that Drosophila and zebrafish models are well-suited to studying human muscle disorders including MDs. 


\section{Drosophila and Zebrafish Models in Understanding the Molecular Basis of Muscular Diseases}

Drosophila and zebrafish models have been used to study human diseases for many years, and have helped us gain a better understanding of the molecular mechanisms underlying these disorders, explore therapeutic strategies and restore normal conditions in affected individuals [8,26-32].

A growing body of new models of muscular diseases is being created using these animals.

For the purpose of this review, we will focus on some particular MDs, namely DMD [33,34], DM1 [35-38] and congenital MD (Walker-Warburg syndrome [39] and CMD Type 1 A [40]), which have been modelled in both fruitfly and zebrafish.

The most common muscular dystrophies are the X-linked, lethal childhood (more severe) DMD and the (less severe) BMD, both caused by mutations in the dystrophin gene. In skeletal muscles, dystrophin associates with various proteins to form a large membrane-bound protein complex called the dystrophin-associated glycoprotein complex (DGC). DGC plays a crucial structural role in linking the actin filaments to the extracellular matrix. Mutation of the dystrophin gene destabilizes this complex and leads to progressive fibre damage, sarcolemma destabilization and leakage $[41,42]$. Comparative genomic studies have shown sequence conservation of dystrophin in vertebrate and invertebrate species including zebrafish and Drosophila [43].

The second MD described, myotonic dystrophy type 1 (DM1), is a neuromuscular disorder caused by a microsatellite CTG repeat expansion in the 3'UTR of the dystrophia myotonica protein kinase (DMPK) gene. Mutated transcripts with expanded repeats accumulate in the nuclei and sequester an alternative splicing factor, called MBNL1, causing foci formation. It leads to splicing defects that can cause a variety of symptoms, ranging from myotonia, muscle weakness to heart symptoms such as arrhythmia or conduction defects [44-47].

Although DM1 is a well-characterized disorder, its molecular mechanisms are not yet fully understood [48].

The third subgroup of MDs described here are the congenital MDs, a heterogeneous group of diseases that include the dystroglycanopathies (caused by mutations in POMT1, POMT2, FKTN, FKRP and other genes), laminin alpha-2 deficiency (CMD 1A), collagen VI-deficient CMD, SEPN1-related CMD, LMNA-related CMD (L-CMD) [49-52] and the most severe congenital MD, Walker-Warburg syndrome (WWS). This rare disorder mainly affects the ocular system and the brain, but also muscles, causing muscle weakness, mental retardation and vision impairment [53]. Several genes are involved in WWS, but major mutations target POMT1 and POMT2 genes [54].

Despite the focus on these three particular subtypes of MD, others have been characterized in Drosophila [33,35,36,39,55-59] and zebrafish [32,37,38,40,60-63] and are listed in Table 1.

\subsection{Drosophila for Disease Modelling and Understanding of Pathogenesis Mechanisms of MD}

As stated above, Drosophila has been used for several decades as a model organism to characterize pathogenesis mechanisms of human diseases. For example, in 2002 Takeyama and co-workers developed a spinobulbar muscular atrophy (SBMA) Drosophila model, consisting of CAG expansion in androgen receptor (AR) gene, and showed that a ligand-dependent activation of AR is necessary for motor neuron degeneration [64]. Similarly, smn hypomorphic mutants [65] were found to recapitulate 
symptoms observed in spinal muscular atrophy (SMA), and this model helped to identify the involvement of the BMP pathway in SMA pathogenesis [66]. Among many others, Drosophila models were also instrumental in gaining insights into the pathogenesis of OPMD [57] and Barth syndrome [67].

Table 1. Major Muscular Dystrophies (MD) modelled in Drosophila and zebrafish.

\begin{tabular}{|c|c|c|c|c|c|c|c|}
\hline \multirow{2}{*}{ Disease } & \multirow{2}{*}{$\begin{array}{c}\text { Mutated } \\
\text { Gene }\end{array}$} & \multicolumn{2}{|c|}{$\begin{array}{l}\text { Animal } \\
\text { Model }\end{array}$} & \multicolumn{2}{|c|}{ Mutation Type in Animal Models } & \multirow{2}{*}{$\begin{array}{l}\text { Shared Symptoms } \\
\text { with Patients }\end{array}$} & \multirow{2}{*}{ Ref. } \\
\hline & & $D$ & $\mathbf{Z}$ & Drosophila & Zebrafish & & \\
\hline \multirow{2}{*}{ DMD/BMD } & \multirow{2}{*}{ Dystrophin } & \multirow{2}{*}{$\checkmark$} & \multirow{2}{*}{$\checkmark$} & \multirow{2}{*}{ Dys deletion mutants } & $\begin{array}{l}\text { Nonsense mutation } \\
\text { in dystrophin gene }\end{array}$ & \multirow{2}{*}{$\begin{array}{c}\text { Age-dependent muscle } \\
\text { degeneration/Loss of muscle } \\
\text { integrity }\end{array}$} & {$[33,55]$} \\
\hline & & & & & $\begin{array}{l}\text { Splice mutation in } \\
\text { dystrophin gene }\end{array}$ & & {$[60-62]$} \\
\hline LGMD & $\begin{array}{c}\text { Lamin A/C } \\
\text { Sarcoglycan } \\
\text { Dysferlin } \\
\text { POMT1 }\end{array}$ & $\checkmark$ & $x$ & $\begin{array}{c}\text { Partial/null } \\
\text { mutations in the } \\
\text { Drosophila } \\
\delta \text {-sarcoglycan locus }\end{array}$ & $x$ & $\begin{array}{c}\text { Reduced lifespan \& mobility } \\
\text { in aged flies }\end{array}$ & {$[56]$} \\
\hline \multirow[b]{2}{*}{ DM1 } & \multirow[b]{2}{*}{ DMPK } & \multirow[b]{2}{*}{$\checkmark$} & \multirow[b]{2}{*}{$\checkmark$} & \multirow{2}{*}{$\begin{array}{l}\text { Expression of CTG } \\
\text { repeats in adult/larval } \\
\text { muscle }\end{array}$} & $\begin{array}{l}\text { MBNL gene } \\
\text { knockdown }\end{array}$ & \multirow{2}{*}{$\begin{array}{l}\text { Myotonia/Muscle defects } \\
\text { Splicing defects } \\
\text { Foci formation }\end{array}$} & {$[35,36]$} \\
\hline & & & & & $\begin{array}{l}\text { Injection of CUG } \\
\text { repeat-containing } \\
\text { mRNA }\end{array}$ & & {$[37,38,68]$} \\
\hline OPMD & PABPN1 & $\checkmark$ & $x$ & $\begin{array}{c}\text { Human PABPN1-17ala } \\
\text { expressed in adult } \\
\text { muscle }\end{array}$ & $x$ & $\begin{array}{l}\text { Progressive muscle } \\
\text { degeneration } \\
\text { Nuclear inclusions }\end{array}$ & {$[57]$} \\
\hline EDMD & $\begin{array}{c}\text { Emerin } \\
\text { Lamin } \mathrm{A} / \mathrm{C}\end{array}$ & $\checkmark$ & $x$ & $\begin{array}{c}\text { Transgenic flies } \\
\text { expressing a mutant } \\
\text { form of Lamin-C } \\
\text { (lacking the first } 42 \mathrm{AA} \text { ) }\end{array}$ & $x$ & $\begin{array}{l}\text { Muscle defects } \\
\text { Early death }\end{array}$ & {$[58,59]$} \\
\hline CMD & $\begin{array}{c}\text { POMT1 } \\
\text { Fukutin } \\
\text { Laminin } \alpha 2\end{array}$ & $\checkmark$ & $\checkmark$ & $\begin{array}{c}\text { Mutants for POMT1 \& } \\
\text { POMT2 Drosophila } \\
\text { orthologs }\end{array}$ & $\begin{array}{l}\text { Point mutation in } \\
\text { laminin } \alpha 2 \text { gene }\end{array}$ & $\begin{array}{c}\text { Shortened lifespan } \\
\text { Age-dependent severity of } \\
\text { muscle phenotypes/Disorder } \\
\text { of primary motor neurons } \\
\text { innervation }\end{array}$ & {$[39,40]$} \\
\hline
\end{tabular}

Notes: Abbreviations: D Drosophila, Z Zebrafish, DMD Duchenne MD, BMD Becker MD, LGMD Limb-Girdle MD, DM1 Myotonic Dystrophy Type 1, OPMD Oculo-Pharyngeal MD, EDMD Emery-Dreifuss MD, CMD Congenital MD. More comprehensive tables of additional models can be found in other recent reviews such as $[32,63]$.

Regarding DMD, the conservation of genes forming the DGC complex and their reduced number makes the fly a good model to study DMD [69]. To model this disease, mutations in Dg and Dys, as well as RNAi lines against these genes, have been generated and analysed. Shcherbata et al. demonstrated mobility defects and age-dependent muscle degeneration and neural defects in $d y s$ mutants [33]. Also, the specific loss of dys in the heart led to an age-dependent disruption of the myofibrillar organization within the myocardium, and to alterations in cardiac performance and development of dilated cardiomyopathy [70]. More recently, a study of the Drosophila DMD model 
exposed to chronic hypoxia revealed impairment of the muscle function in vivo [55]. It has been assumed that systemic hypoxia could contribute to DMD pathophysiology in patients. Moreover, mdx mice (the naturally occurring DMD model) present worsened diaphragmatic dysfunction following hypoxia [71]. These models confirm that Drosophila is a suitable model to study DMD, demonstrating that Dg and Dys interaction is necessary for muscle maintenance, and that the reduced Dys level could explain the degeneration observed in patients.

In addition to DMD, the RNA-dominant disorder DM1 has been modelled in the fruitfly by several groups. First in 2005, Houseley and colleagues showed the sequestration of the MBNL1 orthologue in muscle nuclei by $\mathrm{CTG}_{162}$ toxic repeats, but did not detect any locomotor activity perturbation, muscle defects or reduced lifespan [72]. Shortly afterwards, another DM1 model with 480 interrupted CUG repeats was generated, again showing the accumulation of toxic repeats in nuclear foci, colocalizing with Mbl (MBNL1 orthologue). The DM1 flies exhibited muscle wasting and degeneration, also seen in patients as a result of decreased MBNL1 and increased CUGBP1 levels [35]. More recently, our group generated novel DM1 models consisting of inducible transgenic lines carrying increasing numbers of CTG repeats, which could allow the assessment of effects of CTG repeat size. In addition to foci formation and reduced motility, we observed a hypercontracted phenotype in DM1 larvae, reminiscent of myotonia in patients. It could involve the calcium pump dSERCA, an Mbl splice target because the membrane dSERCA isoform was sufficient to rescue this DM1-induced hypercontraction phenotype in our model. Also, we demonstrated that nuclear accumulation of toxic CUG repeats can affect gene expression independently of splicing [36].

Regarding Walker-Warburg syndrome (WWS), Wairkar and co-workers performed a screen for synaptic abnormalities in Drosophila and identified mutations in POMT1 orthologue, rotated abdomen $(r t)$. They demonstrated that $r t$ is required to glycosylate the Drosophila dystroglycan ortholog Dg in vivo, suggesting that this defective glycosylation in $r t$ mutants could impair synaptic transmission and cause the mental symptoms [73]. Muscle structure and behaviour of knockdown flies for POMT1 and POMT2 orthologues, $r t$ and twisted ( $t w$ ) respectively, have also been analysed by Ueyama et al. [39]. They demonstrated a reduced lifespan, together with locomotion defects and adversely affected muscle structure, also seen in WWS patients. Moreover, they described an age-related worsening of the ultrastructural abnormalities in muscles, associated with excessive apoptosis of myoblasts in the wing disc of $t w$ mutants (POMT2 orthologue) [39]. The authors proposed a new mechanism caused by mutation in POMT genes, involving increased apoptosis that could explain muscle disorganization and muscle defects observed in the disease.

\subsection{Zebrafish Models Designed to Dissect the Molecular Mechanisms of MD}

Among all animal model organisms, many unique advantages of the zebrafish (described above) make it an attractive model for human diseases and for dissecting pathological processes. Zebrafish models have been used, for example, to study congenital and hereditary diseases; carcinogenesis; infection; inflammation and wound healing; immunological, metabolic, endocrine and nutritional diseases; and psychological and behavioural abnormalities, as reviewed in [29].

One of the animal models for DMD investigation are naturally isolated $m d x$ mouse mutants. However, $m d x$ mice have only a mild DMD phenotype owing to the high regenerative capacity of 
mouse muscles [74-76]. Another widely used model to study MD is the zebrafish. Different groups reported that the zebrafish carries an orthologue of the human dystrophin gene, encoding a $400 \mathrm{kDa}$ protein that mimics the subcellular pattern of human dystrophin in adult muscles [77,78]. Large-scale mutagenesis screening in zebrafish has identified a large number of mutants that affect muscle formation, one class of which, called "dystrophic class mutants," presented damaged and disorganized structure of muscles under polarized light. Among them, the sapje (sap) allele has been shown to carry mutation at zf-dystrophin, the zebrafish orthologue of human DMD locus $[13,61,79]$. This nonsense mutation resulting in a premature stop codon within the N-terminal actin-binding domain of dystrophin removes the large muscle-specific isoform, and causes progressive muscle degeneration by disrupting the link between the actin cytoskeleton and the extracellular matrix in skeletal muscles. Compared with the $m d x$ mice, homozygous sap mutant embryos display more severe phenotypes, sharing a large number of similarities with human disease, e.g., humans and zebrafish lack the compensatory levels of utrophin thought to protect $m d x$ mice [80,81]. In homozygous sap mutants, dystrophin deficiency causes a progressive loss of muscle integrity as a result of muscle attachment failure at the embryonic myotendinous junction (MTJ) [62]. It was also found that in sap mutants, fibre degeneration involves separation of the terminal sarcomeres from the terminal sarcolemma, as well as detachment of the terminal sarcolemma from the myoseptum [82]. Furthermore, myofibrils in sap mutants shown by transmission electron microscopy exhibit nuclear condensation indicating cell death [61].

Numerous animal models of DM1 have already been generated, but they all have some limitations. Making use of the advantages of zebrafish, Machuca-Tzili and co-workers applied this model to determine the role of MBNL in DM1 pathogenesis. The morpholino knockdown model showed the essential role of the MBNL2 gene during embryonic development. A lack of mbnl2 caused muscle defects and splicing abnormalities, typical of DM1. An absence of the mbnl2 gene also led to disruption of myofibril organization in skeletal and heart muscles, and reduction of the amount of slow and fast muscles. The phenotypes of mbnl2-morphants were specifically due to mbnl2 knockdown and were rescued with mbnl2 mRNA [37]. More recently, Todd et al. described a new zebrafish model designed to explore the impact of CUG repeat expression during early development. This model of DM1 is based on injection of mRNA, carrying expanded CUG repeats, at a single-cell stage zebrafish embryo. This leads to alteration in fish morphology, behaviour and transcriptional activity during early development. CUG repeat-containing mRNA degrades progressively and is no longer detected after $72 \mathrm{hpf}$; embryos that survive the first $48 \mathrm{~h}$ thus show no significant alterations as adult fish. As stated above, the sequestration of MBNL proteins by CUG RNA is an important pathogenic mechanism of DM. The authors showed that coexpression of zebrafish mbnl2 and CUG RNA suppresses the CUG repeats-mediated toxicity. Thus these studies reveal the influence of toxic CUG repeat-containing mRNA during early development, and suggest that zebrafish DM1 models are attractive tools to conduct small-molecule screening and develop new drug therapies for myotonic dystrophy [38]. The zebrafish DM1 model described above was applied to study the in vitro effects of CUG pseudouridylation [68]. Pseudouridine is an isomerization product of uridine and is the most common structure-stabilizing RNA modification. The studies showed that pseudouridylation of CUG repeats prevents CUG RNA toxicity in the zebrafish DM1 model, implying that the structure of toxic RNAs plays a significant role in the pathogenesis of DM1. These results open new perspectives for the understanding of disease mechanisms and for corresponding drug design. 
Zebrafish is also an excellent animal model to study congenital muscular dystrophies including CMD Type 1 A (CMD 1A) caused by mutation in the human laminin $\alpha 2$ (LAMA2) gene [83]. The $L A M A 2$ mutation leads to muscle degeneration, necrosis, fibrosis and abnormalities in peripheral nerves. $L A M A 2$ plays a crucial structural role in the maintenance of sarcolemmal integrity through its interaction with dystrophin-associated glycoprotein. Hall and co-workers [40] revealed that zebrafish dystrophic mutant candyfloss is the result of mutations in the laminin $\alpha 2$ (LAMA2) gene. The authors demonstrated that early muscle differentiation and myoblast fusion occurred correctly, indicating that deficiency in early Lama2 signalling does not contribute to muscle pathology. However, they observed that innervation by the primary motor neurons was affected. The authors find that muscle tissue damage and subsequent cell death occur through mechanically induced fibre detachments in the absence of sarcolemmal rupture.

\section{Major Advances for MD through Therapeutic Drug Screening in the Fruitfly and Zebrafish}

In this section, fundamental findings in Drosophila and zebrafish models to help cure muscular dystrophies will be discussed. We will focus on drug and genetic screening performed in DMD and DM1 models in both species (Table 2).

Table 2. Screens performed in Drosophila and zebrafish MD models.

\begin{tabular}{|c|c|c|c|c|c|}
\hline $\begin{array}{c}\text { Disease } \\
\text { Model }\end{array}$ & $\begin{array}{c}\text { Animal } \\
\text { Model }\end{array}$ & $\begin{array}{l}\text { Type of } \\
\text { Performed } \\
\text { Screen } \\
\end{array}$ & $\begin{array}{c}\text { Identified Drug/Genetic } \\
\text { Modifier } \\
\text { Mode of Action } \\
\end{array}$ & $\begin{array}{c}\text { Enhanced/Suppressed } \\
\text { Phenotype }\end{array}$ & Ref. \\
\hline \multirow{5}{*}{ DMD } & \multirow{2}{*}{ Drosophila } & \multirow{2}{*}{$\begin{array}{l}\text { Genetic } \\
\text { interactors of } \\
\text { Dys/Dg }\end{array}$} & $\begin{array}{c}\text { Interactors involved in: muscle, } \\
\text { motor \& cystoskeleton function, } \\
\text { neuronal migration or PCP genes, } \\
\text { Notch signaling, TGF- } \beta \text { signaling, } \\
\text { EGFR signaling }\end{array}$ & $\begin{array}{l}\text { Wing-vein phenotype } \\
\text { (anterior and posterior } \\
\text { cross veins } \\
\text { detached/altered cross } \\
\text { veins) }\end{array}$ & \multirow{2}{*}[27,84]{} \\
\hline & & & $\begin{array}{c}\text { Reduction of } m b l \text { levels enhance } \\
\text { muscle phenotypes } \\
\text { Dystrophic flies with reduced } \\
\text { wunen exhibit less age-dependent } \\
\text { degeneration }\end{array}$ & $\begin{array}{l}\text { Abnormal muscle } \\
\text { phenotype }\end{array}$ & \\
\hline & \multirow{3}{*}{ Zebrafish } & & Fluoxetine & $\begin{array}{c}\text { Prevention of membrane } \\
\text { fragility, survival } \\
\text { promotion }\end{array}$ & [85] \\
\hline & & $\begin{array}{l}\text { Drug screening } \\
\text { on sapje and } \\
\text { sapje-like } \\
\text { mutants }\end{array}$ & $\begin{array}{l}\text { Aminophylline, Eprizole, } \\
\text { Homochlorcyclizine } \\
\text { dihydrochloride, Conessine, } \\
\text { Equilin, Pentetic acid, } \\
\text { Proscillaridin A, Sildenafil, } \\
\text { Crassin acetate, Cerulenin, } \\
\text { Prostaglandin }\end{array}$ & \multirow{2}{*}{$\begin{array}{l}\text { Restoration of normal } \\
\text { muscle structure in } \\
\text { affected embryos }\end{array}$} & [86-89] \\
\hline & & $\begin{array}{l}\text { Exon-skipping } \\
\text { antisense } \\
\text { synthetic } \\
\text { oligonucleotides } \\
\text { (ASO) }\end{array}$ & $\begin{array}{l}\text { Aminoglycoside antibiotics } \\
\text { (ataluren-PTC124) }\end{array}$ & & {$[32,90]$} \\
\hline
\end{tabular}


Table 2. Cont.

\begin{tabular}{|c|c|c|c|c|c|}
\hline $\begin{array}{c}\text { Disease } \\
\text { Model }\end{array}$ & $\begin{array}{c}\text { Animal } \\
\text { Model }\end{array}$ & $\begin{array}{c}\text { Type of } \\
\text { Performed } \\
\text { Screen } \\
\end{array}$ & $\begin{array}{c}\text { Identified Drug/Genetic } \\
\text { Modifier } \\
\text { Mode of Action } \\
\end{array}$ & $\begin{array}{c}\text { Enhanced/Suppressed } \\
\text { Phenotype }\end{array}$ & Ref. \\
\hline \multirow{3}{*}{ DM1 } & \multirow[t]{2}{*}{ Drosophila } & $\begin{array}{l}\text { Drug screening } \\
\text { on DM1 flies } \\
\text { (480 interrupted } \\
\text { CTG) }\end{array}$ & $\begin{array}{l}10 \text { suppressor drugs: Non-steroidal } \\
\text { anti-inflammatory agents, } \\
\text { dopamine receptors and } \\
\text { monoamine uptake inhibitors, } \mathrm{Na}^{+} \\
\text {and } \mathrm{Ca}^{2+} \text { metabolism, Muscarinic, } \\
\text { cholinergic and histamine } \\
\text { receptors inhibitors, ... }\end{array}$ & CUG-induced lethality & \multirow[t]{2}{*}[91]{} \\
\hline & & $\begin{array}{l}\text { Genetic modifier } \\
\text { screening on } \\
\text { DM1 flies } \\
\text { (480 interrupted } \\
\text { CTG) }\end{array}$ & $\begin{array}{l}\text { Suppressors: cnc, Nurf-38, foi, } \\
\text { coro, csk, spinster, ... } \\
\text { Enhancers: seven up, viking, } \\
\text { cg4589 }\end{array}$ & $\begin{array}{l}\text { CUG-induced rough-eye } \\
\text { phenotype }\end{array}$ & \\
\hline & Zebrafish & $\begin{array}{l}\text { Drug testing on } \\
\text { DM1 zebrafish } \\
\text { model } \\
\text { (CUG-repeat } \\
\text { expansion } \\
\text { zebrafish model) }\end{array}$ & $\begin{array}{l}\text { Kinase inhibitor (Ro 31-8220) } \\
\text { examination } \\
\text { - additional assay to complement } \\
\text { drug screen performed in cell } \\
\text { culture }\end{array}$ & $\begin{array}{l}\text { Partial rescue of somite } \\
\text { number and length to } \\
\text { width ratio of the tail }\end{array}$ & [92] \\
\hline
\end{tabular}

Notes: Genetic and drug screens performed in Drosophila and zebrafish models of Duchenne muscular dystrophy (DMD) and myotonic dystrophy type 1 (DM1). Abbreviations: PCP Planar Cell Polarity, Dys Dystrophin, Dg Dystrolycan.

The different therapeutic approaches developed to treat neuromuscular disorders and other diseases are (i) gene therapy to repair the mutated gene, either using exon skipping in the case of a missplicing mutation or by adeno-associated virus (AAV) mediated gene delivery to restore the normal copy of a gene; (ii) cell therapy to repair the affected cells that are degenerating in these types of disease; and (iii) drug therapy to treat mainly the consequences of the mutations and to soothe the symptoms [93-96].

These strategies utilize different animal models. The gene and cell therapy approaches are developed mainly using mouse models, whereas major advances have been made using C. elegans, D. melanogaster and the fish D. rerio, due to their compatibility with high-throughput screening (HTS) [26,97]. Drug discovery using mammals can be very costly, and so is often used to test only small sets of compounds [60]. Although cell cultures are more efficient for testing large numbers of molecules, their metabolism may also be completely different from that of a whole organism. Hence, maintaining the physiological contexts in the animals allows a better assessment of the toxicity of the molecules tested.

A variety of small molecules have become available from various academic facilities and companies; for example, Prestwick chemical library (Harvard ICCB) contains 1120 small molecules, composed of $90 \%$ marked drugs and $10 \%$ bioactive alkaloids or related substances. These safe-for-humans compounds were selected for their high chemical and pharmacological diversity [86]. Low molecular weight compounds bind to specific proteins and alter their function, resulting in phenotype changes. 
The use of Drosophila in the screening of compound libraries helped to find potential therapeutic targets for several neurodegenerative disease models including fragile X syndrome (FXS) [66], Alzheimer's disease (AD) [98], fragile X-associated tremor/ataxia syndrome (FXTAS) [99] and more recently, Huntington disease (HD) [100].

Regarding muscular dystrophies, Garcia-Lopez and co-workers used screening on their DM1 Drosophila model to identify modifiers of CUG-induced lethality. Ten suppressor drugs involved in sodium and calcium metabolism were identified and found to improve survival of DM1 flies [91].

The same DM1 model has also been used to identify drugs that can eliminate the CUG-RNA hairpin formation responsible for the sequestration of MBNL1 and splicing defects. Garcia-Lopez and co-workers [101] applied a positional scanning synthetic combinatorial library (PS-SCL) of D-amino acid hexapeptides, and identified a peptide that binds to CUG repeats and suppresses their toxicity. This ABP1 peptide was also able to reverse missplicing in a DM1 mouse model. The discovery of ABP1 as a suppressor of RNA toxicity in both Drosophila and mouse DM1 models supports the view that Drosophila is an accurate model system for developing therapeutics in muscular dystrophies.

Drosophila is also well-suited for the identification of genetic modifiers, and in particular suppressors of pathological phenotypes [102]. Genetic modifier screens have been performed on Drosophila models of spinobulbar muscular atrophy (SBMA) [64], spinal muscular atrophy [103], inclusion body myopathy with early-onset Paget disease and frontotemporal dementia (IBMPFD) [104], and in MD models such as OPMD [57], DM1 [91] and DMD [84]. Regarding DMD, two important genetic interactors have been identified: muscleblind (Mbl) and wunen. The splicing factor Mbl, known to interact with Dg-Dys complex, was found to enhance muscle phenotypes observed in $d y s$ mutants. By contrast, wunen, a human lipid phosphate phosphatase (LPP) 3 homolog, was identified as a suppressor of the dystrophic wing vein phenotype. The wunen-based suppression of $d y s$ mutant phenotypes could be related to an increase in the bioactive lipid sphingosine 1-phosphate (S1P) known to promote cell proliferation and differentiation in many tissues, including muscle. The identification of wunen as a suppressor of DMD-associated muscle degeneration could lead to new DMD therapeutic strategies by elevating S1P signalling to suppress or alleviate the dystrophic muscle symptoms [27]. Further genetic modifier screening performed in ageing dystrophic Drosophila muscles identified interactors of Dys and/or Dg that are involved in stress response pathways and encode proteins involved in communication between muscle and neuron [105]. Likewise, screening was performed in a DM1 model to identify genetic modifiers of the rough eye phenotype, generated by eye-targeted expression of toxic CUG repeats. Garcia-Lopez and co-workers identified 15 genetic modifiers of eye degeneration, among which genes encoding cell adhesion proteins, regulators of gene expression or cell proliferation and actin cytoskeleton components [91]. Moreover, in recent screening for modifiers of eye and muscle degeneration in DM1 model, a genetic interactor of CUGBP1, Smaug (SMAD4A) was identified and found to act as a suppressor of CUG-induced myopathy [106].

The zebrafish, because of its advantages discussed above, and in particular the ability of zebrafish embryos to absorb chemicals, has become a model of choice in screening and testing new drugs $[29-32,61,92]$. This is the case for sapje and sapje-like dystrophin mutants, which are excellent models for DMD therapeutic screens [85-88]. For example, Kawahara and co-workers [87], using easy birefringence assays, have identified seven small molecules that influence muscle phenotypes in sapje mutants. Although chemical treatment did not restore dystrophin expression, three of the seven 
compounds restored normal birefringence and showed increased survival of mutant embryos. Among them, aminophylline showed the greatest ability to restore normal muscle structure in affected embryos. This non-selective phosphodiesterase inhibitor (traditionally used for asthma treatment) increases intracellular cAMP levels, causing activation of the cAMP-dependent protein kinase PKA pathway [87]. Aminophylline-treated fish showed increased levels of phosphorylated PKA, indicating PKA-dependent restoration of muscle structure [86]. Other drug screening carried out on $d y s$ mutants [89] revealed that some aminoglycoside antibiotics (e.g., ataluren-PTC124) can cause read-through of premature stop codon caused by nonsense mutations. Ataluren treatment led to significant improvement of muscle structure and function in sapje mutants accompanied by reexpression of dystrophin.

Another therapeutic strategy involving the zebrafish model is based on the exon-skipping strategy and administration of antisense synthetic oligonucleotides (ASO). Exon skipping partially restores the disrupted reading frame, leading to production of a shorter but still functional dystrophin protein. Statistical and systematic evaluation of exon-skipping in dystrophin-deficient zebrafish mutants demonstrated that the restored dystrophin transcripts represent $10 \%-20 \%$ of the normal dystrophin transcript level, leading to only partial restoration of muscle function, whereas at least $30 \%-40 \%$ is required to recover dystrophic pathology [63,90]. Altogether, the examples presented above illustrate the importance of the zebrafish model in designing and testing therapeutic approaches for muscular dystrophies and in particular for DMD.

\section{Conclusions}

Despite an increasing body of breakthroughs made in the understanding of MDs, the molecular mechanisms underlying many muscle disorders remain poorly understood, limiting the development of efficacious therapies. Technological advances, such as next-generation sequencing (NGS), allow the fast identification of gene variants and pathological mutations in MD patients, while simple animal models such as fruitfly and zebrafish provide means to evaluate their significance. Zebrafish and Drosophila models have been successfully used in the past to uncover cellular and molecular pathways underlying human muscular diseases, reviewed in [3,30,32,107], revealing particular strengths of each model. For example, the zebrafish model, owing to embryo transparency and visual assessment of muscle structure and mobility phenotypes, is well-suited to large-scale drug screening [29,32,87]. The Drosophila model, for which there are large collections of mutants, RNAi lines and other genetic tools, has demonstrated its valuable role in identifying suppressors or enhancers of disease phenotypes through genetic screening [91,97,98].

Overall, this review highlights the role of the zebrafish and Drosophila models in understanding the genetic and molecular basis of human MDs and helping to design therapeutic strategies. As these are simple non-mammalian animal models, the knowledge gained needs appropriate validation before it is applied to treating MD in humans.

\section{Acknowledgments}

We are grateful to the funding agencies listed below that support our work. AFM grant No.19001, ANR grant ID-CELL-SPE, the Equipe FRM-2014 grant to KJ and the Polish State Committee for 
Scientific Research, projects No. 1018/S/IZ/2014 and European Union, European Social Fund grant no. BPZ.506.50.2012.MS to M.D and M.MP.

\section{Author Contributions}

E.P and M.MP contributed to the design of this review and wrote the paper, M.D and K.J coordinated draft preparation.

\section{Conflicts of Interest}

The authors declare no conflict of interest.

\section{References}

1. Emery, A.E. The muscular dystrophies. Lancet 2002, 359, 687-695.

2. Mercuri, E.; Muntoni, F. Muscular dystrophies. Lancet 2013, 381, 845-860.

3. Sparrow, J.; Hughes, S.M.; Segalat, L. Other model organisms for sarcomeric muscle diseases. Adv. Exp. Med. Biol. 2008, 642, 192-206.

4. Rubin, G.M.; Lewis, E.B. A brief history of drosophila's contributions to genome research. Science 2000, 287, 2216-2218.

5. Arias, A.M. Drosophila melanogaster and the development of biology in the 20th century. In Methods in Molecular Biology: Drosophila: Methods and Protocols; Springer: Totowa, NJ, USA, 2008; pp. 1-25.

6. Adams, M.D.; Celniker, S.E.; Holt, R.A.; Evans, C.A.; Gocayne, J.D.; Amanatides, P.G.; Scherer, S.E.; Li, P.W.; Hoskins, R.A.; Galle, R.F.; et al. The genome sequence of Drosophila melanogaster. Science 2000, 287, 2185-2195.

7. Reiter, L.T.; Potocki, L.; Chien, S.; Gribskov, M.; Bier, E. A systematic analysis of human disease-associated gene sequences in Drosophila melanogaster. Genome Res. 2001, 11, 1114-1125.

8. Lloyd, T.E.; Taylor, J.P. Flightless flies: Drosophila models of neuromuscular disease. Ann. N. Y. Acad. Sci. 2010, 1184, e1-e20.

9. Howe, K.; Clark, M.D.; Torroja, C.F.; Torrance, J.; Berthelot, C.; Muffato, M.; Collins, J.E.; Humphray, S.; McLaren, K.; Matthews, L.; et al. The zebrafish reference genome sequence and its relationship to the human genome. Nature 2013, 496, 498-503.

10. Barbazuk, W.B.; Korf, I.; Kadavi, C.; Heyen, J.; Tate, S.; Wun, E.; Bedell, J.A.; McPherson, J.D.; Johnson, S.L. The syntenic relationship of the zebrafish and human genomes. Genome Res. 2000, 10, 1351-1358.

11. Bedell, V.M.; Westcot, S.E.; Ekker, S.C. Lessons from morpholino-based screening in zebrafish. Brief. Funct. Genomics 2011, 10, 181-188.

12. Stainier, D.Y.R.; Kontarakis, Z.; Rossi, A. Making sense of anti-sense data. Dev. Cell 2015, 32, 7-8.

13. Granato, M.; van Eeden, F.J.; Schach, U.; Trowe, T.; Brand, M.; Furutani-Seiki, M.; Haffter, P.; Hammerschmidt, M.; Heisenberg, C.P.; Jiang, Y.J.; et al. Genes controlling and mediating locomotion behavior of the zebrafish embryo and larva. Dev. Camb. Engl. 1996, 123, 399-413. 
14. Gupta, V.; Kawahara, G.; Gundry, S.R.; Chen, A.T.; Lencer, W.I.; Zhou, Y.; Zon, L.I.; Kunkel, L.M.; Beggs, A.H. The zebrafish dag1 mutant: A novel genetic model for dystroglycanopathies. Hum. Mol. Genet. 2011, 20, 1712-1725.

15. Gupta, V.A.; Kawahara, G.; Myers, J.A.; Chen, A.T.; Hall, T.E.; Manzini, M.C.; Currie, P.D.; Zhou, Y.; Zon, L.I.; Kunkel, L.M.; et al. A splice site mutation in laminin- $\alpha 2$ results in a severe muscular dystrophy and growth abnormalities in zebrafish. PLOS ONE 2012, 7, e43794.

16. Hirata, H.; Wen, H.; Kawakami, Y.; Naganawa, Y.; Ogino, K.; Yamada, K.; Saint-Amant, L.; Low, S.E.; Cui, W.W.; Zhou, W.; et al. Connexin 39.9 protein is necessary for coordinated activation of slow-twitch muscle and normal behavior in zebrafish. J. Biol. Chem. 2012, 287, 1080-1089.

17. Saint-Amant, L.; Sprague, S.M.; Hirata, H.; Li, Q.; Cui, W.W.; Zhou, W.; Poudou, O.; Hume, R.I.; Kuwada, J.Y. The zebrafish ennui behavioral mutation disrupts acetylcholine receptor localization and motor axon stability. Dev. Neurobiol. 2008, 68, 45-61.

18. Jinek, M.; Chylinski, K.; Fonfara, I.; Hauer, M.; Doudna, J.A.; Charpentier, E. A programmable dual-RNA-guided DNA endonuclease in adaptive bacterial immunity. Science 2012, 337, 816-821.

19. Irion, U.; Krauss, J.; Nusslein-Volhard, C. Precise and efficient genome editing in zebrafish using the CRISPR/Cas9 system. Development 2014, 4827-4830.

20. Hruscha, A.; Schmid, B. Generation of zebrafish models by CRISPR/Cas9 genome editing. In Neuronal Cell Death; Lossi, L., Merighi, A., Eds.; Methods in Molecular Biology; Springer: New York, NY, USA, 2015; Series Volume 1254, pp. 341-350.

21. Bassett, A.R.; Tibbit, C.; Ponting, C.P.; Liu, J.-L. Highly efficient targeted mutagenesis of Drosophila with the CRISPR/Cas9 system. Cell Rep. 2013, 4, 220-228.

22. Harrison, M.M.; Jenkins, B.V.; O'Connor-Giles, K.M.; Wildonger, J. A CRISPR view of development. Genes Dev. 2014, 28, 1859-1872.

23. Sink, H. Muscle Development in Drosophila; Springer Science \& Business Media, New York, NY, USA, 2007.

24. Baylies, M.K.; Bate, M.; Gomez, M.R. Myogenesis: A view from Drosophila. Cell 1998, 93, 921-927.

25. Saint-Amant, L.; Drapeau, P. Time course of the development of motor behaviors in the zebrafish embryo. J. Neurobiol. 1998, 37, 622-632.

26. Pandey, U.B.; Nichols, C.D. Human disease models in drosophila melanogaster and the role of the fly in therapeutic drug discovery. Pharmacol. Rev. 2011, 63, 411-436.

27. Pantoja, M.; Fischer, K.A.; Ieronimakis, N.; Reyes, M.; Ruohola-Baker, H. Genetic elevation of Sphingosine 1-phosphate suppresses dystrophic muscle phenotypes in Drosophila. Development 2013, 140, 136-146.

28. Vaquer, G.; Dannerstedt, F.R.; Mavris, M.; Bignami, F.; Llinares-Garcia, J.; Westermark, K.; Sepodes, B. Animal models for metabolic, neuromuscular and ophthalmological rare diseases. Nat. Rev. Drug Discov. 2013, 12, 287-305.

29. Lieschke, G.J.; Currie, P.D. Animal models of human disease: Zebrafish swim into view. Nat. Rev. Genet. 2007, 8, 353-367.

30. Maves, L. Recent advances using zebrafish animal models for muscle disease drug discovery. Expert Opin. Drug Discov. 2014, 9, 1033-1045. 
31. Santoriello, C.; Zon, L.I. Hooked! Modeling human disease in zebrafish. J. Clin. Investig. 2012, 122, 2337-2343.

32. Gibbs, E.M.; Horstick, E.J.; Dowling, J.J. Swimming into prominence: The zebrafish as a valuable tool for studying human myopathies and muscular dystrophies. FEBS J. 2013, 280, 4187-4197.

33. Shcherbata, H.R.; Yatsenko, A.S.; Patterson, L.; Sood, V.D.; Nudel, U.; Yaffe, D.; Baker, D.; Ruohola-Baker, H. Dissecting muscle and neuronal disorders in a Drosophila model of muscular dystrophy. EMBO J. 2007, 26, 481-493.

34. Chambers, S.P.; Dodd, A.; Overall, R.; Sirey, T.; Lam, L.T.; Morris, G.E.; Love, D.R. Dystrophin in adult zebrafish muscle. Biochem. Biophys. Res. Commun. 2001, 286, 478-483.

35. De Haro, M.; Al-Ramahi, I.; de Gouyon, B.; Ukani, L.; Rosa, A.; Faustino, N.A.; Ashizawa, T.; Cooper, T.A.; Botas, J. MBNL1 and CUGBP1 modify expanded CUG-induced toxicity in a Drosophila model of myotonic dystrophy type 1. Hum. Mol. Genet. 2006, 15, 2138-2145.

36. Picchio, L.; Plantie, E.; Renaud, Y.; Poovthumkadavil, P.; Jagla, K. Novel Drosophila model of myotonic dystrophy type 1: Phenotypic characterization and genome-wide view of altered gene expression. Hum. Mol. Genet. 2013, 22, 2795-2810.

37. Machuca-Tzili, L.E.; Buxton, S.; Thorpe, A.; Timson, C.M.; Wigmore, P.; Luther, P.K.; Brook, J.D. Zebrafish deficient for Muscleblind-like 2 exhibit features of myotonic dystrophy. Dis. Model. Mech. 2011, 4, 381-392.

38. Todd, P.K.; Ackall, F.Y.; Hur, J.; Sharma, K.; Paulson, H.L.; Dowling, J.J. Transcriptional changes and developmental abnormalities in a zebrafish model of myotonic dystrophy type 1 . Dis. Model. Mech. 2014, 7, 143-155.

39. Ueyama, M.; Akimoto, Y.; Ichimiya, T.; Ueda, R.; Kawakami, H.; Aigaki, T.; Nishihara, S. Increased apoptosis of myoblasts in drosophila model for the walker-warburg syndrome. PLoS ONE 2010, 5, e11557.

40. Hall, T.E.; Bryson-Richardson, R.J.; Berger, S.; Jacoby, A.S.; Cole, N.J.; Hollway, G.E.; Berger, J.; Currie, P.D. The zebrafish candyfloss mutant implicates extracellular matrix adhesion failure in laminin alpha2-deficient congenital muscular dystrophy. Proc. Natl. Acad. Sci. USA 2007, 104, 7092-7097.

41. O’Brien, K.F.; Kunkel, L.M. Dystrophin and muscular dystrophy: Past, present, and future. Mol. Genet. Metab. 2001, 74, 75-88.

42. Guyon, J.R.; Steffen, L.S.; Howell, M.H.; Pusack, T.J.; Lawrence, C.; Kunkel, L.M. Modeling human muscle disease in zebrafish. Biochim. Biophys. Acta 2007, 1772, 205-215.

43. Roberts, R.G.; Bobrow, M. Dystrophins in vertebrates and invertebrates. Hum. Mol. Genet. 1998, 7, 589-595.

44. Brook, J.D.; McCurrach, M.E.; Harley, H.G.; Buckler, A.J.; Church, D.; Aburatani, H.; Hunter, K.; Stanton, V.P.; Thirion, J.P.; Hudson, T.; et al. Molecular basis of myotonic dystrophy: Expansion of a trinucleotide (CTG) repeat at the $3^{\prime}$ end of a transcript encoding a protein kinase family member. Cell 1992, 69, 385.

45. Day, J.W.; Ranum, L.P.W. Genetics and molecular pathogenesis of the myotonic dystrophies. Curr. Neurol. Neurosci. Rep. 2005, 5, 55-59. 
46. Klein, A.F.; Gasnier, E.; Furling, D. Gain of RNA function in pathological cases: Focus on myotonic dystrophy. Biochimie 2011, 93, 2006-2012.

47. Meola, G.; Cardani, R. Myotonic dystrophies: An update on clinical aspects, genetic, pathology, and molecular pathomechanisms. Biochim. Biophys. Acta BBA-Mol. Basis Dis. 2015, 1852, 594-606.

48. Pettersson, O.J.; Aagaard, L.; Jensen, T.G.; Damgaard, C.K. Molecular mechanisms in DM1-A focus on foci. Nucleic Acids Res. 2015, 43, 2433-2441.

49. Bertini, E.; D’Amico, A.; Gualandi, F.; Petrini, S. Congenital muscular dystrophies: A Brief Review. Semin. Pediatr. Neurol. 2011, 18, 277-288.

50. Mercuri, E.; Muntoni, F. The ever-expanding spectrum of congenital muscular dystrophies. Ann. Neurol. 2012, 72, 9-17.

51. Sparks, S.; Quijano-Roy, S.; Harper, A.; Rutkowski, A.; Gordon, E.; Hoffman, E.P.; Pegoraro, E. Congenital muscular dystrophy overview. In GeneReviews $\left({ }^{\circledR}\right)$; Pagon, R.A., Adam, M.P., Ardinger, H.H., Bird, T.D., Dolan, C.R., Fong, C.-T., Smith, R.J., Stephens, K., Eds.; University of Washington: Seattle, WA, USA, 1993.

52. Kirschner, J. Congenital muscular dystrophies. In Handbook of Clinical Neurology; Dulac, O., Lassonde, M., Sarnat, H., Eds.; Pediatric Neurology Part III; Elsevier: Amsterdam, The Netherlands, 2013; Volume 113, Chapter 143, pp. 1377-1385.

53. Dobyns, W.B.; Pagon, R.A.; Armstrong, D.; Curry, C.J.; Greenberg, F.; Grix, A.; Holmes, L.B.; Laxova, R.; Michels, V.V.; Robinow, M. Diagnostic criteria for walker-warburg syndrome. Am. J. Med. Genet. 1989, 32, 195-210.

54. Vajsar, J.; Schachter, H. Walker-Warburg syndrome. Orphanet J. Rare Dis. 2006, 1, 29.

55. Mosqueira, M.; Willmann, G.; Ruohola-Baker, H.; Khurana, T.S. Chronic hypoxia impairs muscle function in the Drosophila model of Duchenne's muscular dystrophy (DMD). PLoS ONE 2010, 5, e13450.

56. Allikian, M.J.; Bhabha, G.; Dospoy, P.; Heydemann, A.; Ryder, P.; Earley, J.U.; Wolf, M.J.; Rockman, H.A.; McNally, E.M. Reduced life span with heart and muscle dysfunction in Drosophila sarcoglycan mutants. Hum. Mol. Genet. 2007, 16, 2933-2943.

57. Chartier, A.; Benoit, B.; Simonelig, M. A Drosophila model of oculopharyngeal muscular dystrophy reveals intrinsic toxicity of PABPN1. EMBO J. 2006, 25, 2253-2262.

58. Dialynas, G.; Speese, S.; Budnik, V.; Geyer, P.K.; Wallrath, L.L. The role of Drosophila Lamin $\mathrm{C}$ in muscle function and gene expression. Dev. Camb. Engl. 2010, 137, 3067-3077.

59. Uchino, R.; Nonaka, Y.; Horigome, T.; Sugiyama, S.; Furukawa, K. Loss of Drosophila A-type lamin $\mathrm{C}$ initially causes tendon abnormality including disintegration of cytoskeleton and nuclear lamina in muscular defects. Dev. Biol. 2013, 373, 216-227.

60. Guyon, J.R.; Goswami, J.; Jun, S.J.; Thorne, M.; Howell, M.; Pusack, T.; Kawahara, G.; Steffen, L.S.; Galdzicki, M.; Kunkel, L.M. Genetic isolation and characterization of a splicing mutant of zebrafish dystrophin. Hum. Mol. Genet. 2009, 18, 202-211.

61. Bassett, D.I.; Currie, P.D. The zebrafish as a model for muscular dystrophy and congenital myopathy. Hum. Mol. Genet. 2003, 12 Spec No 2, R265-R270.

62. Bassett, D.; Currie, P.D. Identification of a zebrafish model of muscular dystrophy. Clin. Exp. Pharmacol. Physiol. 2004, 31, 537-540. 
63. Berger, J.; Currie, P.D. Zebrafish models flex their muscles to shed light on muscular dystrophies. Dis. Model. Mech. 2012, 5, 726-732.

64. Takeyama, K.; Ito, S.; Yamamoto, A.; Tanimoto, H.; Furutani, T.; Kanuka, H.; Miura, M.; Tabata, T.; Kato, S. Androgen-dependent neurodegeneration by polyglutamine-expanded human androgen receptor in Drosophila. Neuron 2002, 35, 855-864.

65. Chan, Y.B.; Miguel-Aliaga, I.; Franks, C.; Thomas, N.; Trülzsch, B.; Sattelle, D.B.; Davies, K.E.; van den Heuvel, M. Neuromuscular defects in a Drosophila survival motor neuron gene mutant. Hum. Mol. Genet. 2003, 12, 1367-1376.

66. Chang, S.; Bray, S.M.; Li, Z.; Zarnescu, D.C.; He, C.; Jin, P.; Warren, S.T. Identification of small molecules rescuing fragile X syndrome phenotypes in Drosophila. Nat. Chem. Biol. 2008, 4, 256-263.

67. Xu, Y.; Condell, M.; Plesken, H.; Edelman-Novemsky, I.; Ma, J.; Ren, M.; Schlame, M. A drosophila model of barth syndrome. Proc. Natl. Acad. Sci. USA 2006, 103, 11584-11588.

68. deLorimier, E.; Coonrod, L.A.; Copperman, J.; Taber, A.; Reister, E.E.; Sharma, K.; Todd, P.K.; Guenza, M.G.; Berglund, J.A. Modifications to toxic CUG RNAs induce structural stability, rescue mis-splicing in a myotonic dystrophy cell model and reduce toxicity in a myotonic dystrophy zebrafish model. Nucleic Acids Res. 2014, 42, 12768-12778.

69. Greener, M.J.; Roberts, R.G. Conservation of components of the dystrophin complex in Drosophila1. FEBS Lett. 2000, 482, 13-18.

70. Taghli-Lamallem, O.; Akasaka, T.; Hogg, G.; Nudel, U.; Yaffe, D.; Chamberlain, J.S.; Ocorr, K.; Bodmer, R. Dystrophin deficiency in Drosophila reduces lifespan and causes a dilated cardiomyopathy phenotype. Aging Cell 2008, 7, 237-249.

71. Farkas, G.A.; Mccormick, K.M.; Gosselin, L.E. Episodic hypoxia exacerbates respiratory muscle dysfunction in DMDmdx mice. Muscle Nerve 2007, 36, 708-710.

72. Houseley, J.M.; Wang, Z.; Brock, G.J.R.; Soloway, J.; Artero, R.; Perez-Alonso, M.; O’Dell, K.M.C.; Monckton, D.G. Myotonic dystrophy associated expanded CUG repeat muscleblind positive ribonuclear foci are not toxic to Drosophila. Hum. Mol. Genet. 2005, 14, 873-883.

73. Wairkar, Y.P.; Fradkin, L.G.; Noordermeer, J.N.; DiAntonio, A. Synaptic defects in a drosophila model of congenital muscular dystrophy. J. Neurosci. 2008, 28, 3781-3789.

74. Bulfield, G.; Siller, W.G.; Wight, P.A.; Moore, K.J. X chromosome-linked muscular dystrophy (mdx) in the mouse. Proc. Natl. Acad. Sci. USA 1984, 81, 1189-1192.

75. Sicinski, P.; Geng, Y.; Ryder-Cook, A.S.; Barnard, E.A.; Darlison, M.G.; Barnard, P.J. The molecular basis of muscular dystrophy in the mdx mouse: A point mutation. Science 1989, 244, 1578-1580.

76. Im, W.B.; Phelps, S.F.; Copen, E.H.; Adams, E.G.; Slightom, J.L.; Chamberlain, J.S. Differential expression of dystrophin isoforms in strains of $\mathrm{mdx}$ mice with different mutations. Hum. Mol. Genet. 1996, 5, 1149-1153.

77. Bassett, D.I.; Bryson-Richardson, R.J.; Daggett, D.F.; Gautier, P.; Keenan, D.G.; Currie, P.D. Dystrophin is required for the formation of stable muscle attachments in the zebrafish embryo. Dev. Camb. Engl. 2003, 130, 5851-5860. 
78. Guyon, J.R.; Mosley, A.N.; Zhou, Y.; O’Brien, K.F.; Sheng, X.; Chiang, K.; Davidson, A.J.; Volinski, J.M.; Zon, L.I.; Kunkel, L.M. The dystrophin associated protein complex in zebrafish. Hum. Mol. Genet. 2003, 12, 601-615.

79. Kunkel, L.M.; Bachrach, E.; Bennett, R.R.; Guyon, J.; Steffen, L. Diagnosis and cell-based therapy for Duchenne muscular dystrophy in humans, mice, and zebrafish. J. Hum. Genet. 2006, 51, 397-406.

80. Deconinck, A.E.; Rafael, J.A.; Skinner, J.A.; Brown, S.C.; Potter, A.C.; Metzinger, L.; Watt, D.J.; Dickson, J.G.; Tinsley, J.M.; Davies, K.E. Utrophin-dystrophin-deficient mice as a model for Duchenne muscular dystrophy. Cell 1997, 90, 717-727.

81. Grady, R.M.; Teng, H.; Nichol, M.C.; Cunningham, J.C.; Wilkinson, R.S.; Sanes, J.R. Skeletal and cardiac myopathies in mice lacking utrophin and dystrophin: A model for Duchenne muscular dystrophy. Cell 1997, 90, 729-738.

82. Collins, C.A.; Morgan, J.E. Duchenne's muscular dystrophy: Animal models used to investigate pathogenesis and develop therapeutic strategies. Int. J. Exp. Pathol. 2003, 84, 165-172.

83. Jones, K.J.; Morgan, G.; Johnston, H.; Tobias, V.; Ouvrier, R.A.; Wilkinson, I.; North, K.N. The expanding phenotype of laminin alpha2 chain (merosin) abnormalities: case series and review. J. Med. Genet. 2001, 38, 649-657.

84. Kucherenko, M.M.; Pantoja, M.; Yatsenko, A.S.; Shcherbata, H.R.; Fischer, K.A.; Maksymiv, D.V.; Chernyk, Y.I.; Ruohola-Baker, H. Genetic modifier screens reveal new components that interact with the Drosophila dystroglycan-dystrophin complex. PLOS ONE 2008, 3, e2418.

85. Waugh, T.A.; Horstick, E.; Hur, J.; Jackson, S.W.; Davidson, A.E.; Li, X.; Dowling, J.J. Fluoxetine prevents dystrophic changes in a zebrafish model of Duchenne muscular dystrophy. Hum. Mol. Genet. 2014, 23, 4651-4662.

86. Kawahara, G.; Kunkel, L.M. Zebrafish based small molecule screens for novel DMD drugs. Drug Discov. Today Technol. 2013, 10, e91-e96.

87. Kawahara, G.; Karpf, J.A.; Myers, J.A.; Alexander, M.S.; Guyon, J.R.; Kunkel, L.M. Drug screening in a zebrafish model of Duchenne muscular dystrophy. Proc. Natl. Acad. Sci. USA 2011, 108, 5331-5336.

88. Kawahara, G.; Gasperini, M.J.; Myers, J.A.; Widrick, J.J.; Eran, A.; Serafini, P.R.; Alexander, M.S.; Pletcher, M.T.; Morris, C.A.; Kunkel, L.M. Dystrophic muscle improvement in zebrafish via increased heme oxygenase signaling. Hum. Mol. Genet. 2014, 23, 1869-1878.

89. Li, M.; Andersson-Lendahl, M.; Sejersen, T.; Arner, A. Muscle dysfunction and structural defects of dystrophin-null sapje mutant zebrafish larvae are rescued by ataluren treatment. FASEB J. 2014, 28, 1593-1599.

90. Berger, J.; Berger, S.; Jacoby, A.S.; Wilton, S.D.; Currie, P.D. Evaluation of exon-skipping strategies for Duchenne muscular dystrophy utilizing dystrophin-deficient zebrafish. J. Cell. Mol. Med. 2011, 15, 2643-2651.

91. Garcia-Lopez, A.; Monferrer, L.; Garcia-Alcover, I.; Vicente-Crespo, M.; Alvarez-Abril, M.C.; Artero, R.D. Genetic and chemical modifiers of a CUG toxicity Model in drosophila. PLoS ONE 2008, 3, e1595.

92. Ketley, A.; Chen, C.Z.; Li, X.; Arya, S.; Robinson, T.E.; Granados-Riveron, J.; Udosen, I.; Morris, G.E.; Holt, I.; Furling, D.; et al. High-content screening identifies small molecules that remove nuclear foci, affect MBNL distribution and CELF1 protein levels via a PKC-independent pathway in myotonic dystrophy cell lines. Hum. Mol. Genet. 2014, 23, 1551-1562. 
93. Blau, H.M.; Springer, M.L. Gene therapy-A novel Form of Drug Delivery. N. Engl. J. Med. 1995, 333, 1204-1207.

94. Chamberlain, J.S. Gene therapy of muscular dystrophy. Hum. Mol. Genet. 2002, 11, 2355-2362.

95. Malik, V.; Rodino-Klapac, L.R.; Mendell, J.R. Emerging drugs for Duchenne muscular dystrophy. Expert Opin. Emerg. Drugs 2012, 17, 261-277.

96. Benedetti, S.; Hoshiya, H.; Tedesco, F.S. Repair or replace? Exploiting novel gene and cell therapy strategies for muscular dystrophies. FEBS J. 2013, 280, 4263-4280.

97. Giacomotto, J.; Ségalat, L. High-throughput screening and small animal models, where are we? Br. J. Pharmacol. 2010, 160, 204-216.

98. McKoy, A.F.; Chen, J.; Schupbach, T.; Hecht, M.H. A novel inhibitor of Amyloid $\beta$ (A $\beta$ ) peptide aggregation from high throughput screening to efficacy in an animal model of alzheimer disease. J. Biol. Chem. 2012, 287, 38992-39000.

99. Qurashi, A.; Liu, H.; Ray, L.; Nelson, D.L.; Duan, R.; Jin, P. Chemical screen reveals small molecules suppressing fragile $\mathrm{X}$ premutation $\mathrm{rCGG}$ repeat-mediated neurodegeneration in Drosophila. Hum. Mol. Genet. 2012, 21, 2068-2075.

100. Schulte, J.; Sepp, K.J.; Wu, C.; Hong, P.; Littleton, J.T. High-content chemical and RNAi screens for suppressors of neurotoxicity in a huntington's disease model. PLoS ONE 2011, 6, e23841.

101. García-López, A.; Llamusí, B.; Orzáez, M.; Pérez-Payá, E.; Artero, R.D. In vivo discovery of a peptide that prevents CUG-RNA hairpin formation and reverses RNA toxicity in myotonic dystrophy models. Proc. Natl. Acad. Sci. USA 2011, 108, 11866-11871.

102. St Johnston, D. The art and design of genetic screens: drosophila melanogaster. Nat. Rev. Genet. 2002, 3, 176-188.

103. Chang, H.C.-H.; Dimlich, D.N.; Yokokura, T.; Mukherjee, A.; Kankel, M.W.; Sen, A.; Sridhar, V.; Fulga, T.A.; Hart, A.C.; Van Vactor, D.; et al. Modeling spinal muscular atrophy in Drosophila. PLOS ONE 2008, 3, e3209.

104. Ritson, G.P.; Custer, S.K.; Freibaum, B.D.; Guinto, J.B.; Geffel, D.; Moore, J.; Tang, W.; Winton, M.J.; Neumann, M.; Trojanowski, J.Q.; et al. TDP-43 mediates degeneration in a novel Drosophila model of disease caused by mutations in VCP/p97. J. Neurosci. 2010, 30, 7729-7739.

105. Kucherenko, M.M.; Marrone, A.K.; Rishko, V.M.; Magliarelli Hde, F.; Shcherbata, H.R. Stress and muscular dystrophy: A genetic screen for Dystroglycan and Dystrophin interactors in Drosophila identifies cellular stress response components. Dev. Biol. 2011, 352, 228-242.

106. De Haro, M.; Al-Ramahi, I.; Jones, K.R.; Holth, J.K.; Timchenko, L.T.; Botas, J. Smaug/SAMD4A restores translational activity of CUGBP1 and suppresses CUG-Induced myopathy. PLoS Genet 2013, 9, e1003445.

107. Phillips, J.B.; Westerfield, M. Zebrafish models in translational research: Tipping the scales toward advancements in human health. Dis. Model. Mech. 2014, 7, 739-743.

(C) 2015 by the authors; licensee MDPI, Basel, Switzerland. This article is an open access article distributed under the terms and conditions of the Creative Commons Attribution license (http://creativecommons.org/licenses/by/4.0/). 